\title{
Os nautai e a promoção do culto de Atená na Sicília do Período Arcaico
}

\author{
The 'nautai' and the promotion of the cult of Athena in Sicily in \\ the Archaic Period
}

Martinho Guilherme Fonseca Soares ${ }^{*}$

\begin{abstract}
Resumo: Este artigo apresenta a condição dos nautai como "protegidos" de Atená, as particularidades de seu ofício no campo da navegação no contexto do expansionismo grego rumo à fundação de suas apoikiai no Mediterrâneo ocidental. Explora os desafios da navegação em alto-mar e, a partir da leitura da Odisseia, de Homero, como Atená foi invocada pelos marinheiros do Período Arcaico em suas travessias. Em seguida, dedicase ao mapeamento dos templos e santuários dedicados à divindade nas apoikiai fundadas em território siciliano ao longo dos séculos VIII e VI a.C., buscando, por fim, destacar os elementos que conduziram à promoção de seu culto como resultado dos modos de intervenção de Atená no campo das tékhnai da navegação.
\end{abstract}

Abstract: This article presents the condition of the 'nautai' as "protected" by Athena, the particularities of their craft in the field of navigation in the context of Greek expansionism towards the foundation of their 'apoikiai' in the western Mediterranean. It explores the challenges of navigation on the high seas and, from reading Homer's Odyssey, how Athena was invoked by sailors from the Archaic Period in their travels. Then, he dedicated himself to mapping the temples and shrines dedicated to divinity in 'apoikiai' founded in Sicilian territory throughout the 8th and 6th centuries $B C$, seeking, finally, to highlight the elements that led to the promotion of his cult as a result of the modes of Athena's intervention in the field of navigation 'tékhnai'.

\author{
Palavras-chave: \\ Odisseia. \\ Nautai. \\ Atená. \\ Sicília. \\ Conectividade.
}

\section{Keywords:}

Odyssey.

Nautai.

Athena.

Sicilia.

Connectivity.

\footnotetext{
* Mestrando em História Social das Relações Políticas pelo Programa de Pós-Graduação em História da Universidade Federal do Espírito Santo (PPGHis/Ufes) sob orientação do Prof. Dr. Gilvan Ventura da Silva. Orcid: <https://orcid. org/0000-0003-1593-3922>.
} 


\section{Os gregos, o auxílio dos deuses e a navegação mediterrânea ${ }^{1}$}

A célebre expressão de Platão (Fédon, 109 a-b) de que os habitantes da Hélade encontravam-se "[...] ao redor do mar, assim como formigas e rãs que vivem em torno de um paul" anuncia para nós a singular familiaridade dos gregos antigos com o espaço marítimo e, por conseguinte, com a navegação. Essa relação, contudo, fora intensificada a partir de meados do século VIII a.C., quando o Mediterrâneo ocidental inexplorado desde a ruína dos palácios micênicos à altura de 1200 a.C. - volta a despontar no horizonte de expectativas das comunidades gregas, ${ }^{2}$ que nele enxergavam múltiplas oportunidades de exploração, notadamente voltadas para a produção agrícola.

Na mesma época e por toda a Antiguidade, circulavam narrativas - de que os poemas homéricos são nosso melhor exemplo - acerca dos navegantes gregos, os quais, tomados por uma particular bravura, enfrentavam a fúria dos mares e suas criaturas monstruosas, caso de Caríbdis, um redemoinho que se formava no Estreito de Messina. Três vezes ao dia, de maneira aterradora, Caríbdis sorvia a água do oceano, levando Homero a aconselhar que marujo algum estivesse na região quando assim o monstro o fizesse, pois, nem mesmo Possêidon, Monarca dos Mares - e apontado em algumas narrativas como progenitor da criatura (GRIMAL, 2005, p. 74) - seria capaz de salvar os nautai e suas embarcações (Odisseia, XII, 101-107). ${ }^{3}$

Pari passu, nas descrições de Homero acerca dos perigos do mar - e por isso a adoção da análise, em especial, da Odisseia, neste texto - emerge uma série de informações sobre aqueles homens que, partilhando um corpo de saberes próprio, se dispunham a encarar o mau tempo e o medo do desconhecido, muitas vezes insuflado por essas narrativas. O poeta os designa, na Odisseia, como os nautai, sujeitos afeitos à marinharia à arte da navegação. Os nautai são responsáveis por carregar a nau com os mantimentos necessários à expedição, Ihe fixar o mastro, içar a vela, aproveitar os ventos e a maré, impulsionar os remos, fazer, enfim, que a embarcação avance frente águas marinhas.

Nessa direção, vemos que a navegação constituía, no interior da sociedade grega, uma atividade para a qual se requeria um conjunto de habilidades de natureza técnica, uma tékhne distinta dos demais ofícios de que se poderia ocupar, por exemplo, um agricultor. O manejo do leme era, assim, totalmente distinto das habilidades requisitadas para a

\footnotetext{
${ }^{1}$ Este artigo reúne resultados obtidos com nossa pesquisa de mestrado realizada entre 2018 e 2020 com apoio da Coordenação de Aperfeiçoamento de Pessoal de Nível Superior (Capes).

${ }^{2}$ Não se trata de afirmar a total interrupção das comunicações na Bacia Mediterrânea a partir de 1200 a.C., mas sim de destacar que as conexões a partir de então deixaram de ser arqueologicamente visíveis ou influentes culturalmente (BOARDMAN, 2006, p. 515).

${ }^{3}$ Um dos epítetos pelos quais o deus é conhecido na Odisseia.
} 
condução do arado, a título de exemplificação. Os nautai eram profissionais itinerantes que, quando chamados, se colocavam a serviço daqueles que melhor lhes pagavam. É dessa forma que Homero os apresenta quando Telêmaco insiste em ir a Pilos e a Esparta em busca de notícias de Odisseu. A contragosto dos nobres de Ítaca, o jovem príncipe anuncia que financiaria, às suas expensas, a expedição por ele, sob o patrocínio de Atená, chefiada (Od., II, 319-321).

O escrutínio dos versos da Odisseia não deixa dúvidas quanto ao estatuto social desses indivíduos. A serviço de um e de outro, como sugere o caso a que nos reportamos, os nautai exerciam funções demiúrgicas. O próprio Homero é quem assinala a natureza do ofício desses a quem os gregos chamavam demiurgos, designando-os como estrangeiros que iam e vinham de um lugar ao outro oferecendo seus serviços como carpinteiros, médicos, construtores, videntes, aedos (Od., XVII, 382-385). Por associação, podemos igualmente atribuir aos nautai a mesma condição sociojurídica ao considerarmos que eles também eram responsáveis pela construção de suas embarcações. Somente é capaz de bem conduzir o navio aquele que conhece toda sua estrutura.

Recorrer a esses homens tornara-se condição primeira para as póleis gregas que, ao longo do Período Arcaico (séculos VIII-VI a.C.), projetavam-se para além dos limites territoriais da Hélade e que, desde o início do século VIII a.C., passavam por uma profunda transformação demográfica, uma verdadeira explosão populacional que tomava lugar em um território marcado pela pobreza dos solos e índices pluviométricos irregulares (POLIGNAC, 1995, p. 21; ALCOCK, 2002, p. 52). ${ }^{4}$ Essas comunidades passam desde logo a (re)ver no Mediterrâneo não mais uma barreira física, mas uma ponte capaz de os conectar a um horizonte mais promissor.

Somado aos fatores ambientais, o sistema jurídico então vigente no mundo grego inviabilizava quaisquer possibilidades de mobilidade social ao concentrar nas mãos dos mais ricos (os arístoi) a quase totalidade das poucas terras produtivas. $\mathrm{O}$ endividamento dos pequenos proprietários e a consequente perda de suas terras para o setor mais abastardo da sociedade asseverava o quadro de crise generalizada, fazendo da carência de alimentos a regra; da fome, uma constante (DOMÍNGUEZ MONEDERO, 2001, p. 46).

Nesse cenário de expectativas reduzidas, geralmente movido por interesses da aristocracia em aumentar suas posses, explorar regiões como a Itália do Sul - a que os gregos chamariam Magna Grécia - e a Sicília, tornara-se uma saída estratégica para atenuar a crise ora instaurada. Residia na necessidade de exploração dessas regiões o

\footnotetext{
${ }^{4}$ Coldstream (2003, p. 86) destaca que esse crescimento populacional variou significativamente de região para região, sendo mais acentuado na Ática. O autor, a título de exemplificação, informa que, em Atenas, a população triplicou ao longo do século VIII a.C., como atestado por um aumento acentuado no número de sepulturas.
} 
recurso ao ofício dos nautai, sujeitos que viabilizariam as expedições marítimas, que, necessariamente, se destinavam a singrar o Mar Mediterrâneo em direção ao Oeste, onde novos assentamentos de tipo permanente foram instalados.

A Sicília, desde o século VIII a.C., foi lócus privilegiado de muitas dessas fundações no Mediterrâneo ocidental, as chamadas apoikiai. ${ }^{5}$ Naxos, a primeira delas, fundada em 734 a.C., segundo informa Tucídides (VI, 3, 1), fora resultado de uma expedição proveniente de Cálcis, na Eubeia. Cumpre destacar, portanto, que o estudo dessas apoikiai nos permite compreender aspectos das novas formas de (re)organização dos "gregos ocidentais" - conforme os chamou pela primeira vez Dunbabin (1948) - aportados longe da Hélade. Dentre esses aspectos, destacam-se as formas de promoção do culto nos novos territórios, que, conforme veremos, esteve marcado, dentre outros fatores, pela relação que os nautai estabelecem em alto-mar com as divindades de seu panteão.

Cabe avaliar, contudo, como se deu essa relação. Singrar o Mar Mediterrâneo não era tarefa simples, principalmente aos nos darmos conta de que os navegantes arcaicos não dispunham de instrumentos eletrônicos ou magnéticos que os auxiliassem a obter a rota desejada. Era preciso recorrer a toda e qualquer informação proveniente do ambiente que os circundava: direção dos ventos, das marés, coloração da água, voo dos pássaros. Residia no emprego desses saberes, o singular ofício dos nautai, sua demiurgia. O conjunto desses saberes constitui as tékhnai da navegação, agrupadas, para fins deste artigo, em dois grupos: "técnicas não instrumentais" e "técnicas instrumentais". Exploremos, a partir de agora, as primeiras.

$\mathrm{Na}$ Antiguidade, os marinheiros contavam, além do auxílio dos deuses, exclusivamente com a força dos remos e velas para impulsionar suas embarcações Mediterrâneo afora, de maneira que o vento se tornava um inimigo formidável, ou um aliado muito útil nessas empreitadas (PRYOR, 1988, p. 13). O uso dos ventos por esses homens não constitui mera consequência de se estar no mar, mas a precisão com que são descritos na Odisseia revela um saber específico, útil à navegação e, por conseguinte, apartado dos conhecimentos relacionados, conforme acima destacamos, ao cultivo da terra. Próximos à ilha de Hélio-Sol, os marujos de Odisseu, cientes dos riscos de ali aportar, ainda que para recobrar as forças, identificam os ventos predominantes por seu aspecto "úmido" e os classificam como perniciosos aos navios (Od., XII, 286).

Em outras passagens da Odisseia, como no canto XIV (456-459), Zeus sopra o enorme Zéfiro sempipluvioso. No mesmo canto (475-482), o aedo descreve outro vento

\footnotetext{
${ }^{5}$ Conforme Longo (2004, p. 6-7), os gregos fizeram uso corrente do termo apoikia com objetivo de indicar que o território fundado era independente da pólis que havia empreendido a fundação. A apoikia se define como um novo território, apartado da metrópole, ou seja, da pólis responsável por sua fundação.
} 
que, vindo dos montes - transmontano -, traz consigo o horror da noite gélida, a neve fria da qual germinam apenas cristais. Tais descrições indicam que os ventos desempenharam a função de uma bússola, uma vez que Odisseu e, por extensão, os navegantes do Período Arcaico, sabiam que "[...] ventos de diferentes quadrantes poderiam ser reconhecidos por suas características físicas: um vento úmido era do Oeste; um vento frio do Norte; e um vento quente e seco, do Sul" (MCGRAIL, 2009, p. 101).

Muito embora um fenômeno meteorológico para nós, ventanias eram, para os navegantes do Período Arcaico, obra dos deuses. Odisseu, liberto das amarras de Calipso, tentava chegar a Ítaca e, à mercê das correntes marinhas e dos ventos, se depara com uma tempestade enviada por Possêidon (Od., VII, 271-277). O deus, quando assim deseja, tem a faculdade de convocar todos os quatro ventos cardinais de uma só vez para o espaço da epopeia (PURVES, 2010, p. 336). É ele quem incita o vendaval, fazendo nevoar a terra e o mar. Reúne os ventos Noto, Euro, Zéfiro e Bóreas no meio do oceano (Od., V, 291-297) e, assim, traz para o cenário da epopeia e para a vida cotidiana dos habitantes da Hélade que, nos poemas, viam não histórias fantasiosas, mas sim uma narrativa fidedigna do modo de intervenção dos deuses, a demonstração dos riscos para aqueles que, inadvertidamente, atentassem contra sua vontade.

A par da inimizade de Possêidon, contudo, Odisseu conta ao longo de toda a Odisseia com o patrocínio e a guarda de Atená. Sua proteção se estende igualmente a Telêmaco, filho do herói. Na expedição por ele chefiada rumo a Pilos e Esparta, Atená faz ressoprar favônio vento (Od., II, 420-421). É a deusa quem, diante dos perigos do mar, permite aos nautai uma travessia segura. Eles, contudo, não confiaram seu destino à proteção divina tão somente, buscando capitanear, ao longo do Período Arcaico, outras técnicas para bem navegarem, de que a Odisseia nos fornece mais exemplos.

Odisseu, ao deixar a ilha de Calipso, onde fora feito refém por sete anos, mira o conjunto das Plêiades, orientando-se também pela Ursa Maior (Od., V, 272-274). Mantendo-a a bombordo, o herói teria indicada a posição do Polo, o que lhe forneceria uma direção fixa da qual outros azimutes poderiam ser estabelecidos. Desse modo, se mantivesse o Polo como direção, ele, em outros termos, estaria dirigindo para o Leste; se apenas para a frente do feixe de luz da escotilha, Norte-Nordeste; se na proa, Nordeste; e assim por diante, no horizonte (MCGRAIL, 2009, p. 101). Vale notar que, ao se orientarem pelas estrelas, os nautai aceleravam suas expedições, já que poderiam também navegar à noite.

Fundamentando-se na Odisseia, Aubreton (1968, p. 167), ao analisar a rota percorrida por Odisseu no caminho de volta a Ítaca, destaca que, assim como o herói, " [...] a maior parte dos marinheiros mediterrâneos, não conhecia mais que a navegação costeira". Por isso, os navegantes arcaicos desenvolveram outra técnica - dentro do grupo das tékhnai 
não instrumentais -, que aqui nos interessa ressaltar: a marcação por terra. Valendo-se das montanhas que desfraldavam por todo o Mediterrâneo, os marinheiros mantinham o topo dessas montanhas sempre à vista (LEFÈVRE, 2013, p. 36), estabelecendo-as como marcos terrestres e, a partir delas, orientando-se.

O Mediterrâneo, contudo, era um mar de surpresas, especialmente no inverno. Braudel (1988, p. 36) assinala que, "[...] para vencer o obstáculo do mau tempo, será necessária a intervenção das modificações técnicas, que certamente demorarão a chegar, como veremos, na construção dos cascos e na acomodação do leme". A Arqueologia, contudo, revela que os gregos investiram em seu aparato tecnológico desde época tão recuada. Oleson (2008) descreve a fabricação de sounding weights - pesos sonoros pelos navegantes do Mediterrâneo antigo, o que abre a análise do segundo grupo de técnicas que acima nominamos "técnicas instrumentais".

Os pesos sonoros eram instrumentos fabricados em chumbo, geralmente em formatos hemisféricos, de sino ou mesmo cônicos. O peso recebe "[...] um furo para amarração [de uma corda] em uma argola robusta ou anel de ferro que the é fixado na extremidade superior, e muitas vezes uma base côncava projetada para conter um pedaço de sebo" (OLESON, 2008, p. 119-121). Um desses pesos foi encontrado em um naufrágio próximo a Gela, apoikia que, segundo Tucídides (IV , 4.3), foi fundada em 689/688 a.C., na Sicília, região a ser explorada neste artigo.

A utilidade dos pesos sonoros é significativa. Oleson (2008, p. 121-122) afirma que o chumbo é o material ideal para audição em cursos d'água, já que possui um elevado poder refletor do som. Além disso, é denso, resistente à corrosão e fraturas, barato e, mais importante, fácil de lançar. Podemos, assim, concluir que as ondas sonoras emitidas quando do peso submerso indicavam, com segurança, a presença de arrecifes na região explorada, podendo os marinheiros, rapidamente, se esvair da zona de perigo. $O$ sebo, preso na parte inferior do instrumento, recuperava amostras de solo, situação em que a acuidade dos nautai, mais uma vez, se fazia presente, na medida em que aspectos como contorno, cor, cheiro, sabor e textura do fundo do mar, uma vez reconhecidos, indicavam a proximidade e/ou distância em relação à terra, haja vista que o tipo de solo varia conforme a proximidade e/ou distância da costa.

Ao disporem dessas habilidades para construção e condução de seus navios, os nautai são reconhecidos como um grupo distinto de demiurgos, o que aproxima suas técnicas de modo singular ao patrocínio de Palas Atená. A deusa, ao lado de Hefestos, apresenta-se essencialmente inventiva e cheia de astúcia (VERNANT, 2013, p. 47; 2000, p. 41), dons necessários a todo aquele que se dispunha a navegar. São os prodigiosos dons de Atená que fazem com que os nautai queiram - assim como Odisseu - sua proteção, 
de modo que a ela delibam em busca de segurança em alto-mar (Od., 430-434), o que nos leva, a partir de agora, a melhor explorar como se processou a intervenção dessa divindade no campo da navegação.

\section{A métis de Atená e a arte da navegação}

O instrumento principal dos nautai é, por excelência, sua nau. Construí-la, de modo a aguentar a pressão constante das ondas, exige a seleção das melhores tábuas de abeto, sua fixação e arremate em um arranjo tão perfeito tal que somente um artífice divino seria capaz de fazê-lo. É este, segundo uma antiga tradição presente em Apolônio de Rodes (Argonáuticas, I, 19-20), um dos tantos regalos de Palas à humanidade. $O$ primeiro navio conhecido, dado ao herói grego Jasão, foi um presente de Atená, deusa inventiva, senhora das múltiplas astúcias, que aos homens concedera, também, o freio, necessário à doma do cavalo (Píndaro, Olimpica, XIII, 65-83). Um terceiro dom: o arado, indispensável para o cultivo da terra, foi, igualmente, invenção da divindade (Sérvio Honorato, Comentários à Eneida, IV).

Atená é apresentada na Odisseia e no mito grego de maneira geral, como a deusa das tékhnai, dos múltiplos saberes. A navegação, vale destacar - com exceção daquela praticada pelos feácios - exige o domínio de técnicas específicas. ${ }^{6}$ A nau não navega sozinha. Sua operação requer, tal como acima aludimos, mãos habilidosas, treinadas na condução do mastro; demanda dos nautai uma acurada capacidade para distinguir os ventos propícios daqueles perniciosos, na expressão adotada por Homero (Od., XII, 286). A navegação, em suma, é resultado do emprego de múltiplas tékhnai. Essencialmente religiosos, os gregos vinham, no amparo divino, a origem dessas técnicas e, no mito, sua explicação. No campo da marinharia não foi diferente, e o conhecimento das técnicas náuticas esteve, conforme nos revela a Odisseia, associado a Atená.

Palas era filha de Zeus e Métis. O primeiro, soberano dos céus, a segunda, deusa da Sabedoria. A própria soberania de Zeus implicava o pleno domínio da métis, o pleno conhecimento. Nenhuma soberania se dá sem métis, sem o socorro da deusa de mesmo nome, "[...] sem o apoio das armas da astúcia de que dispõe sua ciência mágica, o poder supremo não poderia nem se conquistar, nem se exercer, nem se conservar" (DÉTIENNE; VERNANT, 2008, p. 58). Para tornar-se soberano, conta Hesíodo (Teogonia, 889-891),

${ }^{6}$ Os feácios constituem, na llíada e na Odisseia, um povo mítico, cuja habilidade - mágica - para navegar é alvo de constantes referências. 
Zeus, usando de todo o seu ardil, engole Métis, sua primeira esposa, e se apropria de sua essência: o conhecimento, que se traduz para os gregos como métis.

Avançando um pouco mais no mito, vemos que, após engolir a esposa, Zeus, sentindo fortes dores de cabeça, manda que chamem Prometeu e Hefesto ao Olimpo para socorrê-lo. Com um machado duplo os dois desferem um golpe certeiro na cabeça de Zeus e, aos gritos, Atená sai de sua cabeça como uma jovem donzela já toda armada, portando seu capacete, sua lança, seu escudo e a couraça de bronze (VERNANT, 2000, p. 410), o que a torna, uma divindade guerreira, como será, também, cultuada na Sicília. Do nascimento inusitado, Atená herda da mãe os prodigiosos dons da métis, da astúcia, e não podendo os gregos recorrer à Métis, recorriam à deusa que, à semelhança de sua progenitora, dominava múltiplos saberes técnicos e que aos homens tinha a faculdade de conceder.

Por seus dons, Atená - ao lado de Hefesto - é chamada ao patrocínio dos mais diversos ofícios. Da tecelagem à ourivesaria; do cultivo da terra à navegação. No Hino Homérico 20 é cantada como "aquela que obras admiráveis ensinou aos homens que povoam a terra". A prece dos nautai era, assim, para que a deusa os ensinasse a construir a embarcação, que os instruísse na arte de navegar; para que, diante das tempestades, os guarnecessem enviando bons ventos, tal como fizera com Odisseu e Telêmaco, de que as aventuras eram conhecidas por toda a Hélade, onde a potência divina de Palas era definida por "[...] seu modo de intervenção, o que significa, na ocorrência, uma certa maneira de usar esta métis de que Atena é tão prodigamente dotada" (DÉTIENNE; VERNANT, 2008, p. 163).

Conhecedores do modo de intervenção de Atená graças, em grande medida, às narrativas homéricas, a divindade foi amplamente cultuada pelos gregos do Período Arcaico. Atenas é, assim, a "cidade de Atená". Ao se dedicarem a um ofício especializado, a exemplo da tecelagem, ourivesaria, poesia, disputa hípica, agricultura e tantos outros fazeres artesanais, os gregos demandaram a proteção e os dons da deusa cujo pensamento astuto e inventivo era capaz de lhes assegurar êxito. Com os nautai, demiurgos dedicados aos saberes referentes ao reconhecimento das condições climatológicas do mar, à construção e condução de embarcações, não foi diferente.

Confiados à proteção de Atená, os nautai estabeleceram uma relação de proximidade com a deusa em suas expedições, de modo que o espaço marítimo, quando por ela mediado, se tornava propício à navegação, haja visto ser a ela quem faz "ressoprar favônio vento, acima do murmurante oceano vinho" (Od., II, 420-421), em um contexto em que o mar, à luz das proposições de Tuan (2012, p. 171), ao mesmo tempo que detentor de beleza e utilidade, fora, igualmente, para os gregos antigos, uma força escura 
e assustadora o qual, "[...] quando calmo, aparecia com a beleza de um 'vinho escuro', quando bravo, engolia navios e marinheiros". Sob a égide de Atená, o mar converteu-se, para os gregos do Período Arcaico, em uma topofilia.

Conforme assinala Tuan (2012, p. 19; 135), a topofilia é o elo afetivo que se estabelece entre a pessoa, o ambiente físico e o lugar, difuso como conceito, vivido e concreto como experiência pessoal por meio das manifestações específicas do amor humano pelo lugar. É por isso que, no momento de desespero:

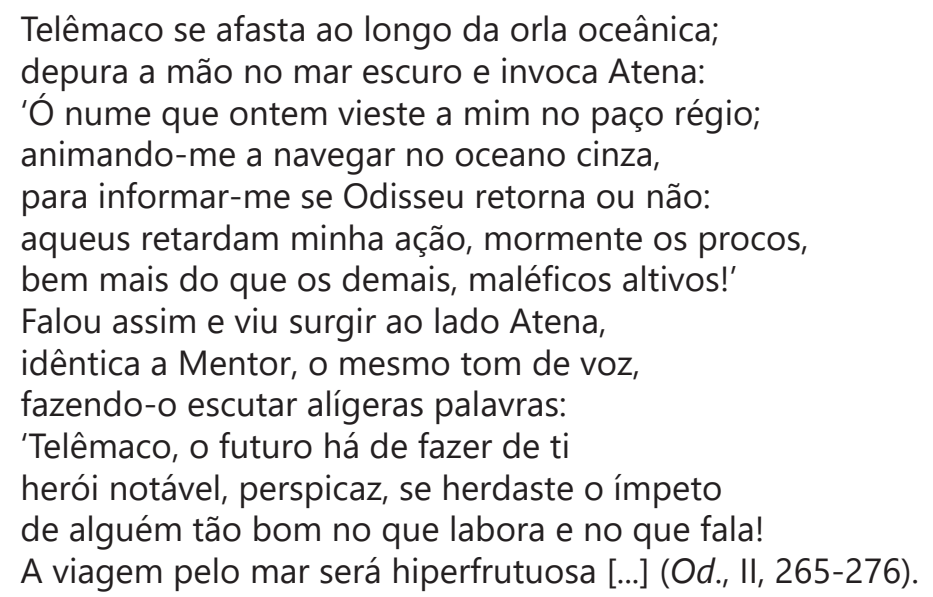

Nessa direção, o poema, conhecido por toda a Hélade, assegura àqueles que, a exemplo de Telêmaco, invocassem a Atená e a ela prestassem culto as condições, as técnicas necessárias para vencer os desafios de se navegar o Mediterrâneo e assim aportar em segurança nos territórios longínquos que os gregos se dispuseram a explorar no Período Arcaico, dos quais a Sicília constitui, nos parágrafos seguintes, nosso ponto de análise.

\section{Os nautai como agentes de promoção do culto a Atená}

A fertilidade dos solos sicilianos contribuiu, sobremaneira, para que a ilha, um verdadeiro continente dada a sua extensão - a maior do Mediterrâneo -, tenha recebido desde os primeiros momentos do expansionismo grego assentamentos de tipo apoikia, seja em sua faixa litorânea, seja na região setentrional. Gregos vindos da Grécia continental, das ilhas do Mar Egeu e da costa da Ásia Menor (LONGO, 2004, p. 6) ocuparam quase toda porção do território, uma terra influenciada pela dinâmica de várias culturas e redes que tornaram a ilha uma importante fronteira na história do Mundo Antigo, moldada de uma só vez por fenômenos locais, regionais e globais (DE ANGELIS, 2016, p. 3). 
A partir do século VIII a.C. em diante, fenícios e gregos ocuparam diversas regiões do Mediterrâneo. Cerca de quinhentos assentamentos gregos permanentes foram estabelecidos em muitas regiões de sua bacia (DE ANGELIS, 2016, p. 49). Para este texto, como sugere o título do artigo, nos detivemos à análise das apoikiai fundadas em território siciliano durante o Período Arcaico, 14 no total, ${ }^{7}$ assim organizadas cronologicamente: Naxos (734 a.C.), Siracusa (733 a.C.), Zancle (730 a.C.), Leontinos (729 a.C.), Mégara Hibleia (729 a.C.), Catânia (728 a.C.), Heloro (700 a.C.), Gela (688 a.C.), Acrai (663 a.C.), Selinonte (651-650 a.C.), Himera (648 a.C.), Casmene (643 a.C.), Camarina (598 a.C.) e Acragas (580 a.C.). Essas apoikiai são apresentadas no Mapa 1.

Mapa 1 - Localização das apoikiai pesquisadas

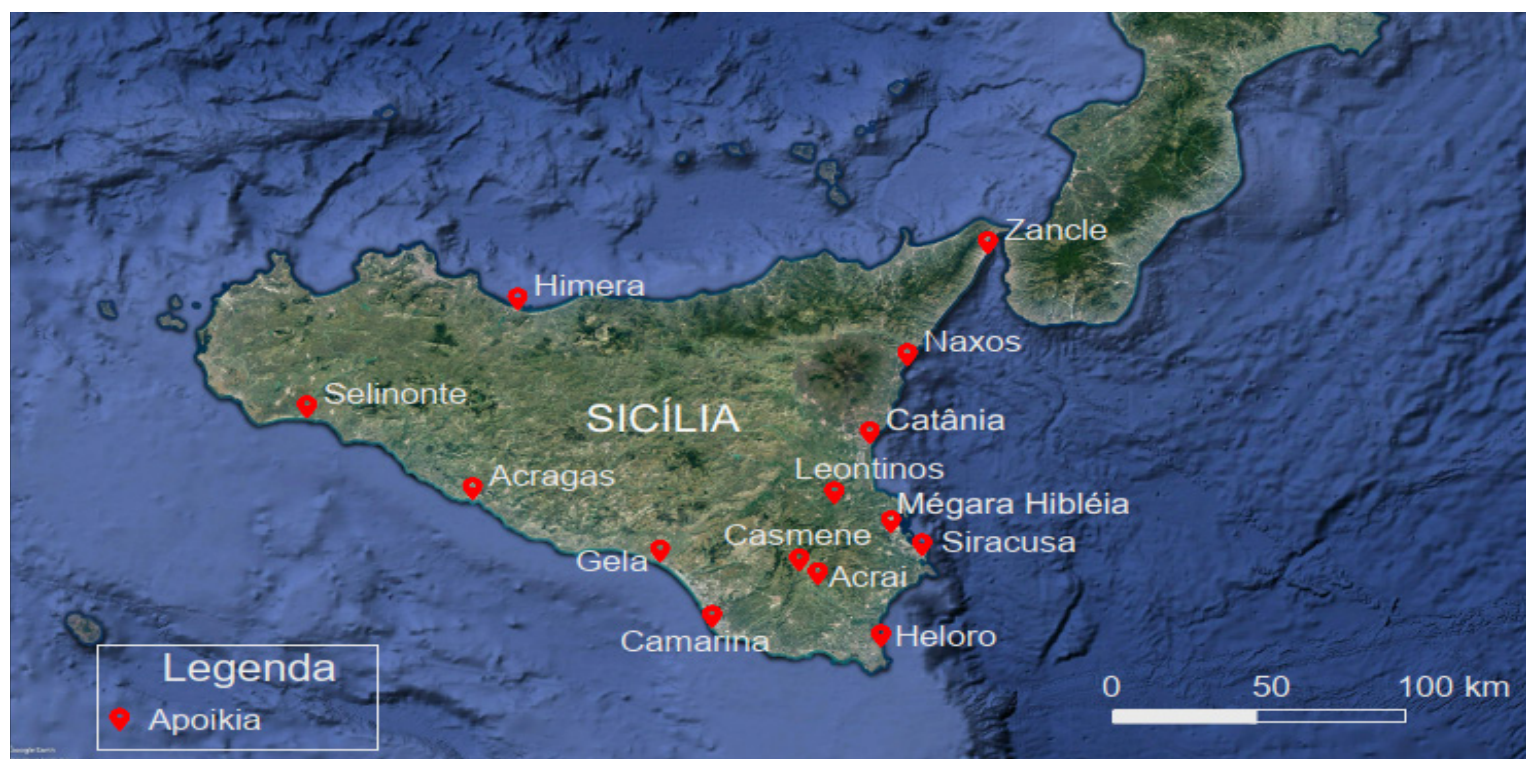

Fonte: Elaborado pelo autor.

Antes, contudo, de avançar na análise dos sítios indicados no Mapa 1 é preciso termos em mente que, ao se estabelecerem nessas regiões, os gregos demandavam novas formas de organização do espaço, em grande medida mediadas por sua experiência religiosa, que, na Sicília, se fez perceber pela presença de templos e santuários. ${ }^{8}$ Conforme assinala Holloway (2000, p. 43), os templos gregos da Sicília são mais numerosos do que os de qualquer parte do mundo grego antigo.

A presença dessas estruturas sacras nos faz perceber que os gregos, na medida em que se instalavam na Sicília, não abandonaram aspectos de sua organização religiosa,

\footnotetext{
${ }^{7}$ A identificação seguiu o inventário de póleis elaborado por Hansen e Nielsen (2004).

${ }^{8}$ Um templo é comumente visto como santuário, mas o contrário, não. Isso porque o santuário pode ser um espaço sem nenhum tipo de edificação, a exemplo de uma fonte sagrada, uma gruta, uma pedra, um bosque, ou mesmo uma árvore.
} 
mantendo, por exemplo, sua estrutura de culto, o que, para Domínguez Monedero (2001, p. 117), revela aspectos constituintes de uma "intercomunicação" entre os ambientes continental e, nesse caso, siciliano. De Angelis (2016, p. 4) expõe que "[...] as duas regiões foram interconectadas e interdependentes durante os períodos Arcaico e Clássico, com a Sicília formando uma região integrante e importante do mundo grego antigo".

Vale observar que a construção desses templos e santuários esteve associada a uma evidente "[...] capacidade de planejar em larga escala, um alto grau de habilidade em engenharia, o recrutamento e a direção de forças de trabalho substanciais e um padrão artístico bem desenvolvido" (TRIGGER, 1990, p. 121) com vistas a satisfazer a organização do território. Conforme revela a análise por nós empreendida nas apoikiai destacadas no Mapa 1, para os gregos ocidentais, esse processo de organização esteve mediado, dentre outros fatores, pelo culto a Atená. Das 14 apoikiai pesquisadas, foi possível identificar, a partir de Veronese (2006), áreas sacras erigidas a Atená em oito delas, a saber: Naxos, Siracusa, Gela, Selinonte, Himera, Casmene, Camarina e Acragas, conforme indica o Mapa 2.

O culto a Atená é o segundo com maior incidência na Sićlia arcaica, sendo o primeiro o de Deméter/Coré, o que pode ser explicado por estarem essas duas divindades ligadas à terra, ao plantio e à colheita. Dedicar culto a elas era fazer cumprir a missão da apoikia, território agrícola por excelência. Cole (2004, p. 9-10) propõe que Deméter, deusa da agricultura, e sua filha, Coré, rainha dos mortos, eram figuras complementares que uniam a paisagem natural, a paisagem cultivada e o reino dos mortos, regulando, assim, o crescimento das culturas que sustentavam a comunidade agrícola da pólis, o que explica o expressivo número de santuários que lhes foram dedicados em território siciliano.

O culto a Deméter/Coré na Sicília fora, portanto, resultado da longínqua relação que os gregos mantinham com as divindades responsáveis pela fertilidade da terra, mas que, dadas as condições ambientais e os interesses sociais e econômicos dos territórios a serem explorados no Mediterrâneo ocidental, passaram por adaptações e foram igualmente fortalecidos. Na mesma direção, entendemos que o culto a outras divindades do panteão helênico seguiu uma lógica semelhante. Parece ser também esse o caso do culto manifestado a Atená em território siciliano, de que os santuários erigidos nos fornecem uma excelente oportunidade de verificação dessa hipótese. 
Mapa 2 - Apoikiai com culto atestado a Atená

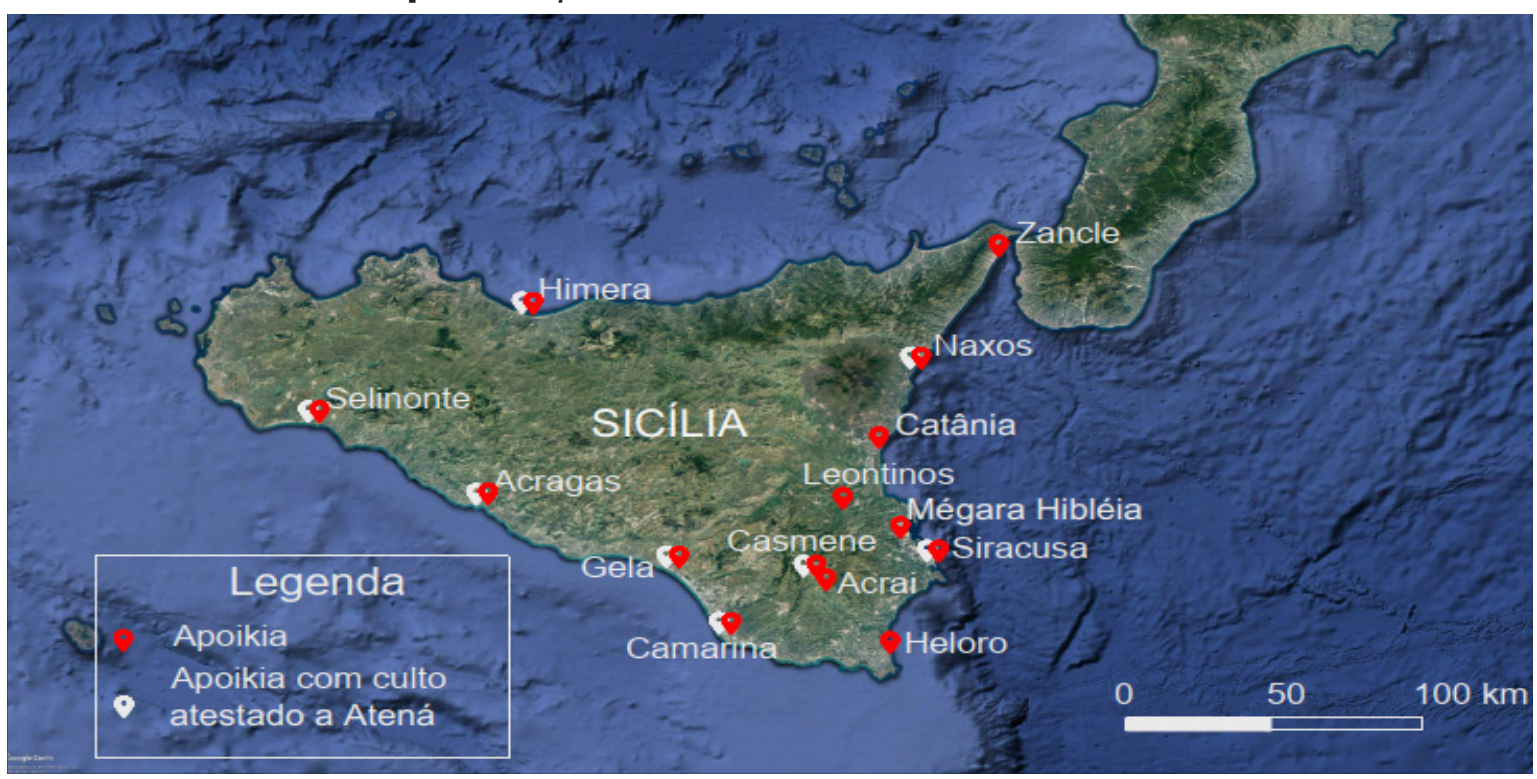

Fonte: Elaborado pelo autor.

Em seu estudo, Veronese (2006) realiza um cuidadoso levantamento das divindades mais cultuadas em todo o território siciliano, conforme disposto no Gráfico 1. Nele, é possível constatar a presença de 10 santuários dedicados a Atená e, conforme resultou de nossa investigação, oito deles erigidos no Período Arcaico, nas apoikiai acima relacionadas.

Gráfico 1 - Relação geral entre o número de santuários e suas divindades titulares

Titolarità del culto

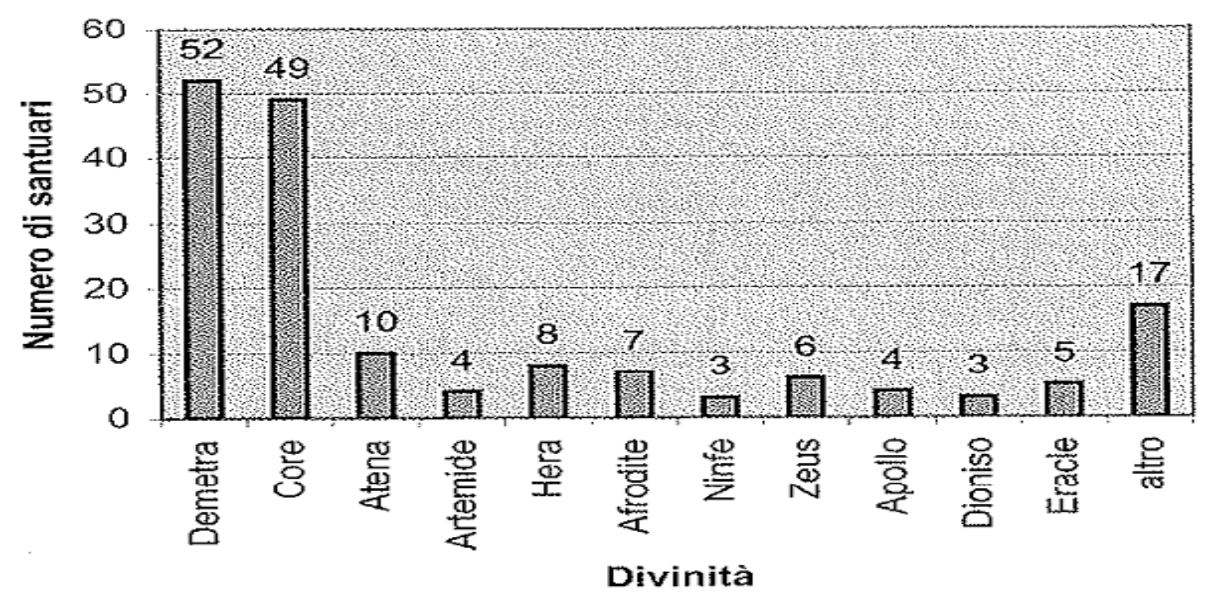

Fonte: Veronese (2006, p. 545).

Nesses assentamentos, em 90\% dos casos, Atená é homenageada na cidade ou em seus arredores imediatos (VERONESE, 2006, p. 545), o que reforça as ligações da deusa 
com o espaço marítimo, já que essas áreas adjacentes comportam a estrutura portuária de cada apoikia, mas também porque, conforme Cole (2004, p. 17), as primeiras póleis identificaram Atená como divindade capaz de trazer segurança à comunidade. Dados os limites deste texto, nos ateremos, à guisa de conclusão, à análise do templo de Atená erguido em Siracusa, apoikia que, segundo Tucídides (VI, 3.2), foi:

[...] fundada no ano seguinte [ao da fundação de Naxos] por Arquias, da família dos Heráclidas, que vindo de Corinto, primeiro expulsou os sículos da ilha no que antes se referia ao interior da cidade e que agora já não está completamente rodeada pelas águas; mais tarde, com o passar do tempo, a cidade exterior estaria anexada à outra dentro de uma área amuralhada e também se tornaria muito populosa.

Seguindo os cálculos de Tucídides, o ano de 733 a.C. corresponde ao da fundação de Siracusa, uma vez que, segundo o mesmo autor, Naxos foi fundada em 734 a.C. Essa apoikia apresentou, desde os primeiros anos de sua fundação, um caráter fortemente expansionista, tendo fundado Camarina, na costa sudoeste, em 598 a.C.; Acrai, em 663 a.C., e Casmene, vinte anos depois (LONGO, 2004, p. 58, 72). Eloro é fundada com os mesmos propósitos por volta de 700 a.C. (DE ANGELIS, 2016, p. 95).

A fundação dessas apoikia de segunda geração - já que originárias de uma outra apoikia - estava associada ao ideal das póleis gregas que, de modo geral, se caracterizava por relações competitivas. Cada pólis, cada apoikia, desejava, acima de tudo, a conquista do poder (FLORENZANO, 2019, p. 149), que, no caso siracusano e das demais apoikiai sicilianas, se expressou na ampliação de suas posses territoriais. Segundo Longo (2004, p. 72), Heloro, Acrai e Casmene foram, na verdade, centros criados com um objetivo muito específico: o de garantir o controle do território siracusano contra as ameaças das outras cidades gregas e de sua população nativa.

Não tendo a busca pela expansão territorial sido uma particularidade de Siracusa, De Angelis (2016, p. 4) indica que as apoikiai sicilianas estavam a caminho de se tornarem Estados de muito sucesso. Para o autor, o impressionante desenvolvimento físico e espacial de cada uma se deu em razão de serem lideradas por elites que se organizaram em clãs e que, assim, controlavam rigidamente a distribuição de terras, mantendo suas posições no topo da hierarquia social e buscando expandir suas posses e consequente poder político-econômico, ${ }^{9}$ que resultou em grandes projeto arquitetônicos, a exemplo do templo de Atená, em Siracusa (Figura 1).

\footnotetext{
${ }_{9}^{9}$ As apoikiai experimentaram sucessivas tiranias ao longo de sua história. Os casos mais conhecidos são de Gela e Siracusa, conforme relata Tucídides.
} 
Figura 1 - Templo de Atená em Siracusa

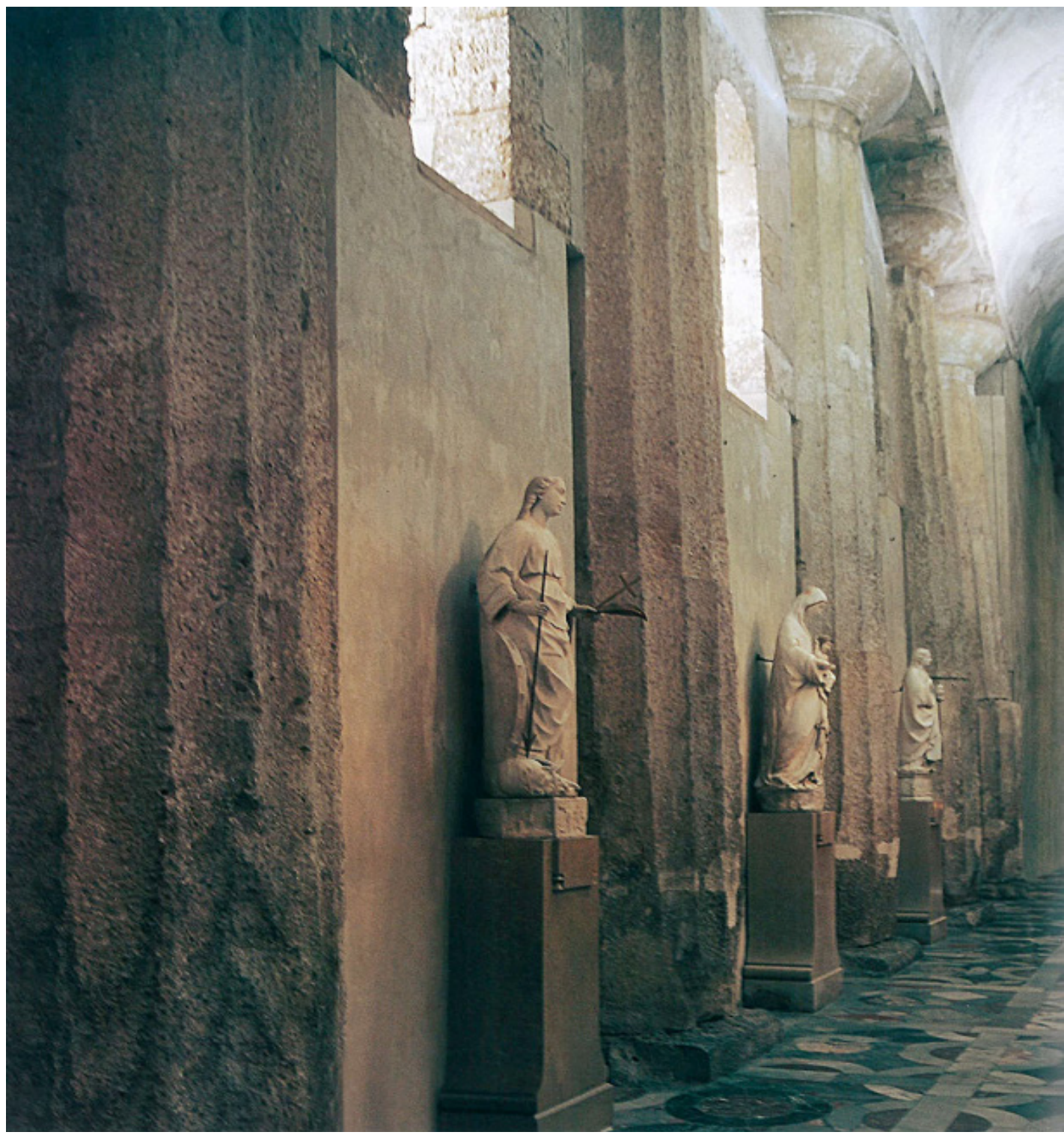

Fonte: Longo (2004, p. 64)

Ao analisarmos a monumentalização dos espaços sagrados nessas apoikiai, percebemos que este processo esteve a serviço da manutenção de relações de poder controladas pelas elites locais, como resultado das conexões entra a Grécia continental e suas apoikiai. O templo de Atená, em Siracusa, é um edifício que data do Período Arcaico e que possui $22,2 \mathrm{~m}$ de largura por $55,45 \mathrm{~m}$ de altura (DE ANGELIS, 2016, p. 103) e um frontão abrigando a estátua de Atená, cujo escudo dourado, brilhando sob os raios do Sol, representava um ponto de referência para os marinheiros (LONGO, 2004, p. 65). A própria monumentalização das estruturas sacras em território siciliano é fruto das conexões mantidas com a Grécia continental, onde o templo de pedra surgira no século VIII a.C. (STARR, 1962, p. 190). 
Conforme indica a Figura 1, o templo de Atená constitui, de fato, uma obra de arquitetura monumental, demandando pelo menos 600.000 horas-homem de trabalho (DE ANGELIS, 2016, p. 103). Tal escala de construção e sua exuberância chamam a atenção, dentre outros fatores, para o grau de experiência requisitado aos que se dedicaram à sua construção e decoração, mais ainda por se tratar de um edifício cuja estrutura excedia em muito o que suas funções cultuais exigiriam (TRIGGER, 1990, p. 121). Nessa perspectiva, o templo de Atená, em Siracusa, atesta a existência de um Estado organizado responsável por sua instalação, tal como propõe Trigger (1990, p. 12).

A estrutura ressalta, ademais, que tais espaços serviram à formação de uma comunidade, que, colocada sob a guarda do escudo de Atená, buscava, na deusa, a proteção necessária para fazer frente às dificuldades impostas pelo território a ser desbravado. De Himera, ${ }^{10}$ procede uma imagem de culto de Atená (Figura 2), que, feita em bronze, ressalta os atributos guerreiros da divindade.

Figura 2 - Bronze de Atená (início do século VI a.C.)

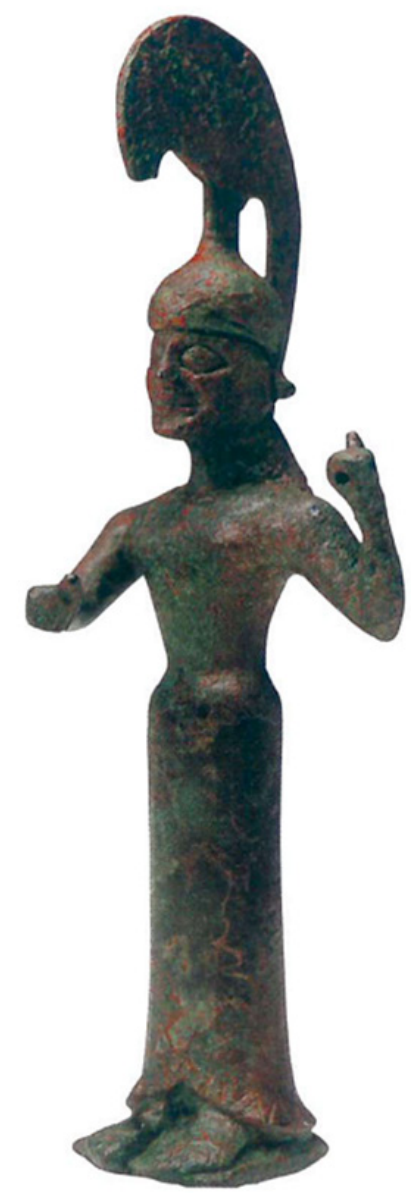

Fonte: Jannelli (2004, p. 48).

${ }^{10}$ Himera foi uma apoikia fundada por Zancle, conforme nos dá testemunho Tucídides $(\mathrm{VI}, 5,1)$. 
É diante desse quadro mais amplo que vemos Atená sendo invocada nos poemas homéricos como divindade patrona dos nautai e que, a partir de dados arqueológicos, a encontramos igualmente cultuada na Sicília, onde vislumbramos a tentativa, por parte da população siciliota (gregos e não gregos), em alcançar as benesses que à deusa estavam associadas, o que derivou de um intenso grau de conectividade entre os povos residentes na Sicília e aqueles que haviam há uma, duas ou mais gerações, sido responsáveis pelos assentamentos, agora, helenizados.

Na medida em que Palas Atená assegurava sucesso na travessia marítima, também ela garantiria êxito para as apoikiai que lhe prestassem culto em seus projetos de expansão territorial. Deusa guerreira, Atená se faria igualmente presente no campo de batalha, sustentando a causa daqueles que lhe prestavam culto diante das populações inimigas com que se enfrentavam com relativa frequência, o que promoveu seu culto como divindade belicosa, tal como indica seus atributos na Figura 2, onde vemos a deusa equipada com seu capacete de guerra.

Nessa direção, alçada à condição de patrona dos nautai, conforme revelam os versos da Odisseia, Atená seria agente divina daqueles que, sob sua proteção ancestral, Ihe mantivessem culto em terra firme, honrando-a com a construção de templos e santuários. Tê-la por perto era garantia de que, assim como protegera os helenos em alto-mar, a deusa cuidaria dos assentamentos, assegurando a produção do solo com seus inventos, protegendo-os de povos invasores. "Palas Atená, protetora da cidade, dá-nos sorte e prosperidade", canta o poeta no Hino Homérico 11. Ao cultuarem Atená em alto-mar, os gregos expedicionários foram, assim também, responsáveis pela promoção de seu culto na Sicília do Período Arcaico, reconhecendo na deusa a capacidade de promover topofilias no espaço de suas apoikiai de maneira a difundir seu culto por toda a Bacia Mediterrânea.

\section{Referências}

\section{Documentação textual}

APOLONIO DE RODAS. Argonáuticas. Introducción, traducción y notas de Mariano Valverde Sánchez. Madrid: Gredos, 1996.

HESÍODO. Teogonia: a origem dos deuses. Tradução de Jaa Torrano. São Paulo: Iluminuras, 2017.

HOMERO. Odisseia. Tradução de Trajano Vieira. São Paulo: Editora 34, 2011.

PÍNDARO. Ode Olímpica XIII. Tradução e comentário de Tiago Bentivoglio da Silva. In: SILVA, T. B. Tradução e comentário à $13^{a}$ Olímpica de Píndaro. 2015. 104 f. Dissertação 
(Mestrado em Letras Clássicas) - Programa de Pós-Graduação em Letras Clássicas, Universidade de São Paulo, São Paulo, 2015.

PLATÃO. Fédon. Tradução de Jorge Paleikat e João Cruz Costa. São Paulo: Abril Cultural, 1972.

SERVIVS HORONATVS. Servii Grammatici Qui Feruntur in Vergilii Carmina Commentarii. Edited by G. Thilo and Hermann Hagen. Cambridge: Cambridge University Press, 2011.Volume 1.

TUCÍDIDES. Historia de La Guerra del Peloponeso: libros V-VI. Traducción y notas de Juan José Torres Esbarranch. Madrid: Gredos, 1992.

\section{Documentação arqueológica}

HANSEN, M; H.; NIELSEN, T. H. An inventory of archaic and classical poleis. New York: Oxford University Press, 2004.

JANNELLI, L. Imera. In: JANNELLI, L.; LONGO, F. (Ed.). I Greci in Sicilia. Verona: Arsenale, 2004, p. 44-49.

LONGO, F. Eloro, Acre e Casmene. In: JANNELLI, L.; LONGO, F. (Ed.). I Greci in Sicilia. Verona: Arsenale, 2004, p. 72-79.

LONGO, F. Introduzione. In: JANNELLI, L.; LONGO, F. (Ed.). I Greci in Sicilia. Verona: Arsenale, 2004, p. 6-11.

VERONESE, F. Lo spazio e la dimensione del sacro: santuari greci e territorio nella Sicilia Arcaica. Pádua: Esedra, 2006.

\section{Bibliografia instrumental}

HAESBAERT, R. Território e multiterritorialidade: um debate. Geographia, n. 17, p. 19-46, 2007.

TRIGGER, B. G. Monumental architecture: a thermodynamic explanation of symbolic behavior. World Archaeology, v. 22, n. 2, p. 119-132, 1990.

TUAN, Y. Topofilia: um estudo da percepção, atitudes e valores do meio ambiente. Londrina: Eduel, 2012.

\section{Obras de Referência}

GRIMAL, P. Dicionário da mitologia grega e romana. Rio de Janeiro: Bertrand Brasil, 2005. 


\section{Obras de apoio}

ALCOCK, S. O meio ambiente. In: CARTLEDGE, P. (Ed.). História ilustrada da Grécia antiga. São Paulo: Ediouro, 2002, p. 48-71.

AUBRETON, R. Introdução a Homero. São Paulo: Edusp, 1968.

BOARDMAN, J. Greeks in the East Mediterranean (South Anatolia, Syria, Egypt). In: TSETSKHLADZE, G. R. (Ed.) Greek colonisation an account of Greek colonies and other settlements overseas. Boston: Brill, 2006, p. 507-534. v. 1.

BRAUDEL, F. O espaço e a história no Mediterrâneo. São Paulo: Martins Fontes, 1988.

BURKERT, W. Religião grega na Época Clássica e Arcaica. Lisboa: Fundação Calouste Gunbenkian, 1993.

COLDSTREAM, J. N. Geometric Greece (900-700 B.C). New York: Routledge, 2003.

COLE, S. G. Landscapes, gender, and ritual space: the ancient Greek experience. London: University of California Press, 2004.

DE ANGELIS, F. Archaic and classical Greek Sicily: a social and economic history. New York: Oxford University Press, 2016.

DÉTIENNE, M.; VERNANT, J. Métis: as astúcias da inteligência. São Paulo: Odysseus, 2008. DOMÍNGUEZ MONEDERO, A. J. La polis y la expansion colonial griega (siglos VIII-VI). Madrid: Sintesis, 2001.

DUNBABIN, T. J. The western greeks: the history of Sicily and South Italy from the foundation of the greek colonies to 480 B.C. Oxford: Claredon Press, 1948.

FLORENZANO, M. B. B. Definindo a pólis: o papel das fronteiras na integração do espaço políade. In: FLORENZANO, M. B. B. (Org.). Khoríon - Xopíon: cidade e território na Grécia antiga. São Paulo: Intermeios, 2019, p. 147-160.

HOLLOWAY, R. R. The archaeology of ancient Sicily. London: Routledge, 2000.

LEFÈVRE, F. História do mundo grego antigo. São Paulo: Martins Fontes, 2013.

MCGRAIL, S. Boats of the world: from the stone age to medieval times. Oxford: Oxford University Press, 2009.

OLESON, J. P. Testing the waters: the role of sounding weights in ancient Mediterranean navigation. Memoirs of the American Academy in Rome, v. 6, p. 119-176, 2008.

POLIGNAC, F. Cults, territory and the origins of the Greek City-State. London: University of Chicago Press, 1995.

PRYOR, J. H. Geography, technology and war: studies in the maritime history of the Mediterranean, 649-1571. New York: Cambridge University Press, 1988.

PURVES, A. C. Wind and time in Homeric epic. Tapa, v. 140, n. 2, p. 323-350, 2010.

RIBEIRO JR., W. A. (Org.). Hinos homéricos. São Paulo: Unesp, 2010. 
STARR, C. The origins of Greek civilization (1100-650 b.C.). London: Jonathan Cape, 1962. VERNANT, J. P. As origens do pensamento grego. Rio de Janeiro: Difel, 2013.

VERNANT, J. P. O universo, os deuses, os homens. São Paulo: Companhia das Letras, 2000. 